\title{
Massive cerebral air embolism after blunt chest trauma with full neurological recovery
}

\author{
Georg Reith, MD*; Bertil Bouillon, MD*; Samir G. Sakka, MD'; Jerome M. Defosse, $\mathrm{MD}^{\dagger}$; \\ Axel Gossmann, $\mathrm{MD}^{\ddagger}$; Christian Probst, $\mathrm{MD}^{*}$
}

\section{ABSTRACT}

Cerebral air embolism (CAE) is a common, often lethal, complication in blunt and penetrating chest trauma. The factors affecting the outcome of CAE patients are poorly understood, and there is no generally accepted treatment algorithm. In this report, we present the case of a 28 -year-old male motorcyclist with a massive $\mathrm{CAE}$, including bilateral internal carotid artery air on computed tomographic examination following blunt chest trauma. With prehospital intubation, oxygen, transfusion, and open laparotomy but without any specific treatment regarding the CAE, a follow-up computed tomography (CT) scan approximately 6 hours later showed resolution of the cerebrovascular air. Recovery was unremarkable, and the patient was discharged neurologically intact after 22 days.

\section{RÉSUMÉ}

L'embolie gazeuse cérébrale (EGC) est une complication fréquente mais souvent mortelle des traumas thoraciques contondants ou pénétrants. Les facteurs qui influent sur I'issue de l'EGC sont mal compris, et il n'y a pas d'algorithme généralement reconnu de traitement. Sera exposé dans l'article le cas d'un homme de 28 ans, qui a subi un accident de motocyclette et chez qui s'est formée une EGC massive, touchant entre autres les deux artères carotides internes, consécutive à un trauma contondant du thorax, et visible à la tomodensitométrie (TDM). On a procédé à l'intubation en phase préhospitalière, à l'administration d'oxygène, à des transfusions et à une laparotomie effractive, mais on n'a pas appliqué de traitement particulier à l'égard de l'EGC; une TDM de suivi, effectuée environ 6 heures plus tard, a révélé la disparition de la présence d'air dans le réseau vasculaire cérébral. Après avoir connu une évolution normale, le patient a quitté I'hôpital, sans séquelles neurologiques, au bout de 22 jours.

Keywords: arterial air embolism, blunt chest trauma, bronchial fistula, treatment options, neurological recovery

\section{INTRODUCTION}

First described by Morgagni in 1769, systemic air embolism is a frequently reported event following blunt and penetrating chest trauma, as well as iatrogenic interventions. ${ }^{1,2}$ It is estimated that systemic air embolism occurs in $4 \%-14 \%$ of all cases of chest trauma, ${ }^{3,4}$ with mortality rates of $80 \%$ in blunt and $48 \%$ in penetrating chest trauma, making early detection crucial. ${ }^{5}$

Hemoptysis in blunt chest trauma strongly suggests the existence of a communication channel between the airways and the pulmonary blood vessels, which can only be proven in $22 \%$ of cases with a confirmed air embolism. ${ }^{5}$ Continuous echocardiography can detect intravascular air by identifying bubbles in the cardiac cavities. ${ }^{6}$

From a pathophysiological view, air enters the pulmonary venous system when the intravascular pressure is lower than the bronchial/alveolar air pressure and is the basis for avoiding high pressure ventilation settings in these patients. ${ }^{4,7,8}$ Systemic air embolism triggers neurological dysfunction. It has been suggested that $2 \mathrm{~mL}$ of air in the cerebral arteries can be fatal. ${ }^{4}$

Several therapeutic options based on physiological principles have been published. Unilateral lung ventilation when only one hemithorax is affected can be accomplished by purposeful mainstem bronchus intubation, by using a double lumen tube, by blocking the affected bronchus with an endobronchial blocker, or by hilar clamping during emergency thoracotomy. ${ }^{9}$ In order to reduce ventilation pressure, high-frequency jet ventilation has been used in cases where cerebral air embolism (CAE) was found or suspected. ${ }^{10} \mathrm{~A}$ high fraction of inhaled oxygen $\left(\mathrm{FiO}_{2}\right)$ near 1.0 can increase the arterial oxygen content but will also remove

From the Departments of *Trauma and Orthopedic Surgery; †Anesthesiology and Operative Intensive Care Medicine; and ¥Radiology, CologneMerheim Medical Center (CMMC), Witten/Herdecke University, Witten, Germany.

Correspondence to: Dr. Georg Reith, Klinik für Orthopädie, Unfallchirurgie und Sporttraumatologie, Ostmerheimer Straße, 200, D-51109 Köln, Germany; Email: reithg@kliniken-koeln.de 
dissolved nitrogen from the blood, speeding the dissolution of bubbles because of an increased pressure gradient of nitrogen between the bubbles and blood. ${ }^{4,11}$

Finally, hyperbaric oxygen therapy (HBOT) is widely accepted as the ideal treatment option for systemic air embolism, although this indication is controversial. ${ }^{12,13}$ Hyperbaric oxygenation is assumed to decrease the physical size of the bubbles and may increase bubble denitrogenation by forming a higher gradient of dissolved oxygen between the blood and the air bubble. ${ }^{12-15}$ Logistic and transport limitations of HBOT render it impractical, and the restricted access to the patient in the hyperbaric chamber precludes its immediate use for a multitrauma patient.

\section{CASE REPORT}

\section{History}

A 28-year-old male, helmeted driver of a motorcycle was admitted to the emergency department (arrival time 0855) via helicopter after he was involved in a motor vehicle accident with a passenger car (accident time 0730). The prehospital physician noted that the patient was vomiting and had a Glasgow Coma Scale of E1 M2 $\mathrm{V} 4$ prior to intubation at the accident scene. On arrival to the hospital, the patient had reduced left-sided breath sounds, a tender abdomen, and anisocoria. His vital signs were heart rate $108 / \mathrm{min}$, blood pressure $80 /$ $40 \mathrm{~mm} \mathrm{Hg}$, and pulse oximetry of $80 \%$ while being ventilated at a minute volume of $7 \mathrm{~L} / \mathrm{min}, 12$ breaths/ min, a PEEP $5 \mathrm{cmH}_{2} \mathrm{O}$, and $\mathrm{FiO}_{2}$ of 1.0. A laceration of the left eyebrow was noted, but there were no remarkable external neck injuries or puncture, or extremity injuries. He had received $2 \mathrm{~L}$ of Ringer's lactate prior to arrival as well as vasopressors, and initial blood work showed $\mathrm{Hb}$ $12.7 \mathrm{~g} / \mathrm{dL}, \mathrm{INR} 1.14, \mathrm{BE}-1 \mathrm{mmol} / \mathrm{L}, \mathrm{pH}$ 7.27.

A chest radiograph at 0910 showed a total atelectasis of the left lung and right main bronchus intubation. Cerebral CT scan at 0915 showed a massive intracranial air embolism (Figure 1a [arrows]), as well as air in the brachiocephalic trunk and the internal carotid arteries on both sides. A small hemorrhage in the left thalamus and in the right frontal operculum were also detected. Chest CT identified bilateral (left > right) lung contusion, aspiration, splenic rupture, liver laceration, and mesenteric bleeding.

A left-sided chest tube had been placed on arrival for absent breath sounds on the left. After the right mainstem bronchus was identified radiographically, the endotracheal tube was withdrawn at 0914, and a central venous catheter was inserted at 0920 . The patient was taken to the operating room for emergency laparotomy, with a suture of the liver capsule and splenectomy at 1010. During surgery, $600 \mathrm{~mL}$ of autologous blood were retransfused with two additional units of packed red blood cells and six units of fresh frozen plasma. The postoperative CT scan (approximately 6 hours after admission, at 1530) showed complete resolution of the abnormal air in the cranium and thorax, whereas the extent of the intracerebral hemorrhage remained unchanged (see Figure 1b). No signs of cerebral ischemia were detected at any time.

HBOT was initially considered but, ultimately, not performed due to these CT scan results.

During the 10-day intensive care unit course, intracranial pressure was measured using an intracranial transducer, and mean cerebral perfusion pressure was maintained at $60-80 \mathrm{~mm} \mathrm{Hg}$. The target arterial $\mathrm{pO}_{2}$ was $500-600 \mathrm{~mm} \mathrm{Hg}\left(\mathrm{FiO}_{2} 0.9\right)$ with an arterial $\mathrm{pCO}_{2}$ $35-40 \mathrm{~mm} \mathrm{Hg}$ for the initial 24 hours.

Follow-up CT scan on day 1 after admission again showed intracerebral hemorrhages in the left thalamus and the right frontal operculum, but again no cerebrovascular air and no cerebral ischemic areas, whereupon arterial $\mathrm{PaO}_{2}$ was set $>80 \mathrm{~mm} \mathrm{Hg}$.

A magnetic resonance imaging (MRI) of the head on day 3 after admission showed no evidence of ischemic areas alongside small hematomas in the left thalamus, the right frontobasal, as well as the postcentral region and in the superior frontal gyrus. A small subarachnoid hemorrhage was seen on the tentorium.

On day 6, sedation was tapered, and the patient was extubated without complications. From days 6 to 11 , the patient showed clinical signs of post-trauma delirium and retrograde amnesia with respect to the accident. On day 11, the patient was transferred to the general ward where he still showed slight cognitive deficits but no focal neurological signs. A follow-up MRI (day 13) and an electroencephalogram (EEG) (day 14) were unremarkable. On day 22, the patient was discharged home with completely normal neurological functions.

\section{DISCUSSION}

This case is notable for an excellent outcome compared to a mortality rate of $80 \%$ in patients with arterial air embolisms after blunt chest trauma and $20 \%$ of patients 
(a)

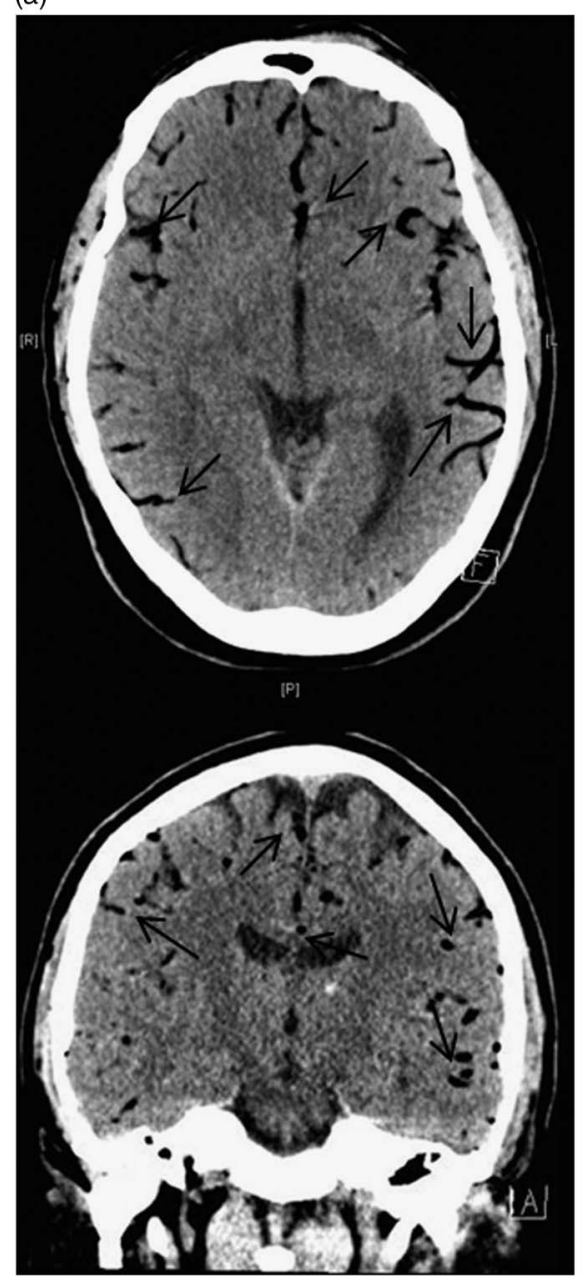

(b)

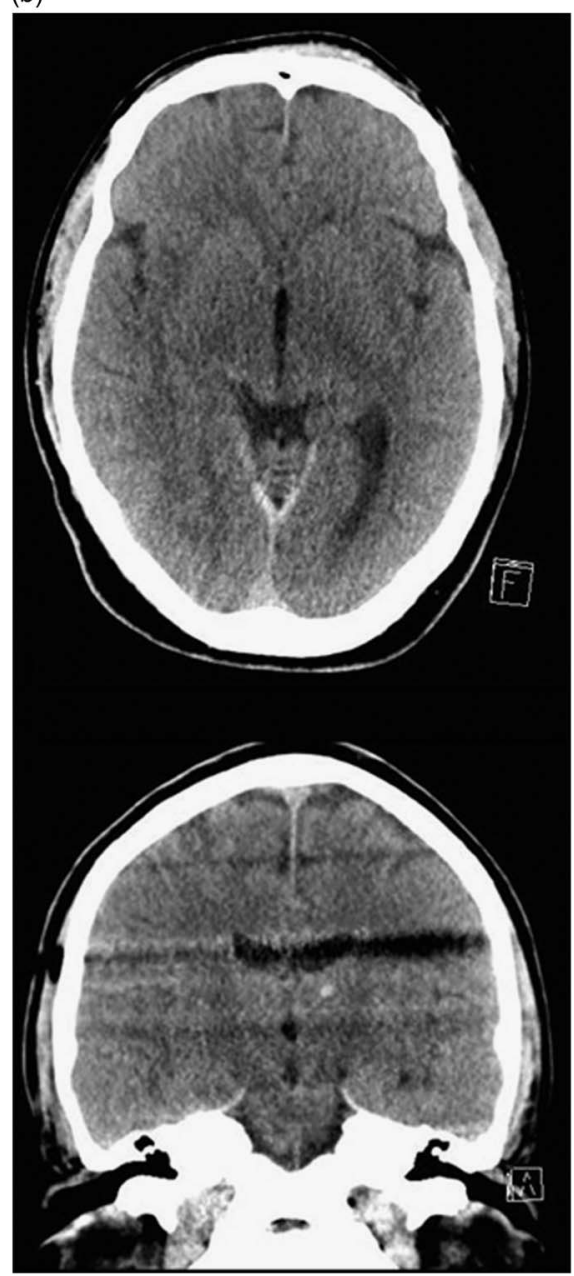

Figure 1. Computed tomography: Transverse and coronal slice of the head. (a) Immediately after admission (arrows on intravascular air). (b) Approximately 6 hours after admission.

with severe neurological deficiencies after CAE. ${ }^{5}$ Notably, in this case, besides advanced trauma life support and standard intensive care therapy with a higher $\mathrm{pO}_{2}$ for one day, no specific treatment concerning the diagnosis CAE was applied.

Neurological outcome without neurological deficits implies that no ischemic areas developed in the brain, after blood flow was discontinued by gas. Therefore, one might speculate that the air embolism did not last long enough, and $\mathrm{O}_{2}$ content was sufficiently high. We assume that the initial CT scan was taken at just the right time to find the intravascular cerebral air. However, the source of this "momentary cerebral air embolism" remains unclear. In theory, there may be a high number of unreported cases of very short-term embolic situations that are not routinely diagnosed.

Is there an explanation for that outstanding neurological recovery besides concluding that there was only minimal damage to the bronchial system without ongoing air leakage into the circulation? We think there could have been some more advantages that the patient had, mainly by coincidence but which are in accordance with the pathophysiological considerations and some of the treatment suggestions. First, by accident, only the less injured right lung was ventilated with high pressure because of right-sided intubation, which is one of the recommended treatment options.?

Second, by chance, the injured left lung was not ventilated before a chest tube was applied. Thereby a prolonged hyperbaric situation in the injured lung was prevented. The first two aspects seem important taking into account further case reports presenting fatal pathology that initially began with the start of positive pressure ventilation. ${ }^{8}$

Third, also by chance, when ventilation of the left lung started by repositioning the endotracheal tube 
proximal to the carina, pure oxygen ventilation was already established. Because the patient was ventilated with pure oxygen only, the body had the best chances to reabsorb the gas as fast as possible. This is in line with investigations by Annane et al. who showed that the rate of air removal in cerebral arteries of dogs was much faster when normobaric pure oxygen $\left(\mathrm{FiO}_{2}\right.$ 1.0) was ventilated compared to ambient air $\left(\mathrm{FiO}_{2} 0.21\right)$. In conclusion, the imaging and detection of this embolism was only possible due to improvements of radiological diagnostics, which are faster and better than before. Due to this consideration, it could occur that cases similar to the described one will be reported more often. In consequence, it needs more investigations to recheck existing outcome results of CAE in chest trauma, which were developed mainly out of autopsy data from the eighties.

\section{Why should an emergency physician be aware of this?}

In our opinion, considering the existing data and the described case, we conclude some points that should be tried in treating patients with chest trauma preclinically. First, it is crucial to think of the possibility of air embolism already at the scene of the accident/ trauma. Furthermore, the indication for inserting a chest tube in chest trauma should be handled quite broadly. Besides ventilation with pure oxygen from the beginning, passing the endotracheal tube past the carina into the right main bronchus in case of isolated leftsided chest traumas may be an option in selected cases but cannot be given as a broad recommendation. ${ }^{16}$

Competing interests: None declared.

\section{REFERENCES}

1. Fries CC, Levowitz B, Adler S, et al. Experimental cerebral gas embolism. Ann Surg 1957;145(4):461-70.
2. Saada M, Goarin JP, Riou B, et al. Systemic gas embolism complicating pulmonary contusion. Diagnosis and management using transesophageal echocardiography. Am 7 Respir Crit Care Med 1995;152(2):812-5.

3. Trunkey D. Initial treatment of patients with extensive trauma. N Engl 7 Med 1991;324(18):1259-63.

4. Ho AM, Ling E. Systemic air embolism after lung trauma. Anesthesiology 1999;90(2):564-75.

5. Yee ES, Verrier ED, Thomas AN. Management of air embolism in blunt and penetrating thoracic trauma. 7 Thorac Cardiovasc Surg 1983;85(5):661-8.

6. Glenski JA, Cucchiara RF, Michenfelder JD. Transesophageal echocardiography and transcutaneous $\mathrm{O} 2$ and $\mathrm{CO} 2$ monitoring for detection of venous air embolism. Anesthesiology 1986;64(5):541-5.

7. Campbell PR, Kerridge R. Fatal traumatic air embolism following a stab wound to the chest. Aust N Z J Surg 1993; 63(4):307-9.

8. Yadav S, Jain S, Aggarwal P, et al. Systemic arterial air embolism: positive pressure ventilation can be fatal in a patient with blunt trauma. BMF Case Rep 2013;2013: epub, 1-4.

9. Brederlau J, Muellenbach RM, Wunder C, et al. Delayed systemic air embolism in a child with severe blunt chest trauma treated with high-frequency oscillatory ventilation. Can 7 Anaesth 2011;58(6):555-9.

10. Gotz-Albrod S, Knuttgen D, Paul A, et al. Arterial air embolism as a complication of blunt thoracic trauma. Anaesthesist 1999;48(7):452-4.

11. Annane D, Troche G, Delisle F, et al. Effects of mechanical ventilation with normobaric oxygen therapy on the rate of air removal from cerebral arteries. Crit Care Med 1994; 22(5):851-7.

12. Weenink RP, Hollmann MW, Vrijdag XC, et al. Hyperbaric oxygen does not improve cerebral function when started 2 or 4 hours after cerebral arterial gas embolism in swine. Crit Care Med 2013;41(7):1719-27.

13. Bothma PA, Heij RE. Despite animal studies, HBOT is the treatment of choice for cerebral gas embolism. Diving Hyperb Med 2013;43(4):249.

14. Bessereau J, Genotelle N, Chabbaut C, et al. Long-term outcome of iatrogenic gas embolism. Intensive Care Med 2010;36(7):1180-7.

15. Souday V, Radermacher P, Asfar P. Cerebral arterial gas embolism-a race against time! Crit Care Med 2013;41(7):1817-9.

16. Kubota H, Kubota Y, Toyoda Y, et al. Selective blind endobronchial intubation in children and adults. Anesthesiology 1987;67(4):587-9. 